\title{
Radionuclide Evaluation of Postextrasystolic Potentiation of Left Ventricular Function Induced by Atrial and
}

\section{Ventricular Stimulation}

VICTOR KALFF, MBBS, FRACP WILLIAM CHAN, MBBS, FRACP MARK RABINOVITCH, MD, FRCP(C) WILLIAM O'NEILL, MD JOSEPH WALTON, MD JAMES STEWART, MD JAMES $H$. THRALL, MD BERTRAM PITT, MD, FACC

Ann Arbor, Michigan
From the Department of Internal Medicine, Divisions of Cardiology and Nuclear Medicine, University of Michigan Medical Center, Ann Arbor, Michigan. This work was supported by a travel grant from Australian National Heart Foundation, Canberra, Australia (Dr. Kalff), the Fogarty Foundation, U.S. Public Health Service, Bethesda, Maryland (Dr. Chan) and a research fellowship from the Canadian Heart Foundation, Ottawa, Ontario, Canada (Dr. Rabinovitch). Manuscript received November 3,1981 ; revised manuscript received January 25, 1982, accepted February 11, 1982.

Address for reprints: Bertram Pitt, MD, Division of Cardiology, University of Michigan Medical Center, 1405 E. Ann Street W11611, Ann Arbor, Michigan 48109.
Postextrasystolic potentlation of left ventrlcular function induced by ventricular and atrial stimulation was compared in 10 patients using radionuclide ventriculography. After insertion of pacing wires, a preliminary radionuclide ventriculogram was obtained and then ventricular and atrial trigeminy was induced in random order, each with identical R-R coupling intervals, each for 6 to 10 minutes. During the stimulation studies, radionuclide data were acquired in electrocardiographic gated list mode format. Left ventricular ejection fraction and relative end-diastolic and end-systolic volume changes were measured for each reformatted composite sinus, atrial and ventricular premature beat and potentiated beat. The volume changes were normalized to the count-based values obtained for the sinus beat of the appropriate study. Postextrasystolic potentiation induced by either ventricular or atrial stimulation was characterized by similar significant increases in left ventricular ejection fraction (mean \pm standard deviation $7 \pm 3$ percent, $p<0.01$ versus $7 \pm 5$ percent, $p<0.01$; difference not significant [NS]) and decreases in relative end-systolic volume $(-12$ \pm 12 percent, $p<0.01$ versus $-12 \pm 8$ percent, $p<0.01$; NS) but little change in relative end-diastolic volume $(+5 \pm 10$ percent, NS versus +4 \pm 7 percent, NS; NS). This was despite a longer compensatory pause $(1,120 \pm 220$ versus $1,050 \pm 190 \mathrm{~ms}, p<0.01)$ after the ventricular premature beat. It is concluded that there is no difference in the postextrasystolic potentiation induced by atrial or ventricular premature stimulation.

In patients with angina pectoris, myocardial asynergy may be due to myocardial scarring or ischemia, or both. Those with myocardial ischemia may have improved global left ventricular function and regional myocardial wall motion after successful myocardial revascularization, ${ }^{1-3}$ whereas little if any improvement can be expected in those with myocardial scarring. Several methods to identify preoperatively those with potentially salvageable myocardial segments have been investigated, including pharmacologic intervention with norepinephrine ${ }^{4}$ or nitroglycerin. ${ }^{5}$ However, the most useful predictor of myocardial viability appears to be the change in ventricular function evoked by postextrasystolic potentiation. ${ }^{6}$

Postextrasystolic potentiation after induction of ventricular premature beats has been shown to be an excellent predictor of myocardial viability, inotropic reserve ${ }^{7,8}$ and morbidity and mortality after coronary bypass graft surgery. ${ }^{9,10} \mathrm{~A}$ limitation has been the need to induce ventricular premature beats, which have the potential for provoking sustained ventricular arrhythmias, especially in the group of patients with ischemic heart disease and impaired left ventricular function. Recently, in animal studies, ${ }^{11}$ atrial premature beats were shown to demonstrate some potentiation in the following cardiac cycle, thereby potentially reducing the risk of premature stimulation. The purpose of this study 
was to compare in human subjects the postextrasystolic potentiation elicited by atrial premature beats with that evoked by ventricular premature beats using radionuclide ventriculography.

\section{Methods}

Study patients: Informed consent was obtained from 10 patients -5 women and 5 men (mean age 54, range 36 to 68 years) - about to undergo diagnostic cardiac catheterization. Six were found to have significant coronary artery disease, one cardiomyopathy and three normal left ventricular function and normal coronary arteries; all had normal sinus rhythm and none had a history of tachycardia or bradyarrhythmias (Table I). Each patient underwent an uncomplicated standard cardiac catheterization including measurement of left and right heart hemodynamics, contrast ventriculography and selective coronary angiography using either the Sones or Judkins technique. All cardioactive drugs were continued until the time of the study and each patient was appropriately fasted.

Cardiac pacing: At the end of cardiac catheterization, arterial hemostasis was obtained and then two $4 \mathrm{~F}$ pacing catheters were inserted into the vein used for the right heart study. One catheter was positioned in the apex of the right ventricle and the other placed in a variable location in the right atrium, the only criterion for positioning being stable capture. A brief period of cardiac pacing was carried out using a Laboratory Savita model GSO orthorhythmic cardiac pacemaker while the patient was still in the catheter laboratory. With use of a programmable option, continuous ventricular and then atrial trigeminy was induced to screen for the development of sustained cardiac arrhythmias and to confirm adequate placement of pacing wires.

Radionuclide ventriculography: The patients were then injected with stannous pyrophosphate, 25 millicuries $(\mathrm{mCi})$ of technetium-99m pertechnetate and transferred to the nuclear cardiac suite. Radionuclide ventriculography was performed using a General Electric gamma camera with the patient supine under a small field of view $(20 \mathrm{~cm})$. Imaging data were collected in a modified left anterior oblique projection to allow optimal separation of the right and left ventricular

\section{TABLE I}

Mean Cycle Lengths of the Stimulation Studies (ms)

\begin{tabular}{lccc}
\hline & $\begin{array}{c}\text { Sinus } \\
\text { Beat }\end{array}$ & $\begin{array}{c}\text { Coupling } \\
\text { Interval }\end{array}$ & $\begin{array}{c}\text { Compensatory } \\
\text { Pause }\end{array}$ \\
\hline $\begin{array}{l}\text { Rest study } \\
\text { Atrial trigeminy }\end{array}$ & $890 \pm 160^{*}$ & -- & - \\
Ventricular trigeminy & $800 \pm 170^{*}$ & $595 \pm 90$ & $1050 \pm 190^{*}$ \\
\hline${ }^{*} p<0.01$ when compared with equivalent ventricular trigeminy & \\
data.
\end{tabular}

blood pools. Data were acquired on a Medical Data Systems computer with a 20 megabyte multiplatter storage disc.

A baseline 16 frame 64 by 64 matrix equilibrium gated blood pool scan was collected followed by two electrocardiographic gated list mode studies. Each of the latter studies was acquired at a frame rate of $1 \mathrm{~ms}$, lasted 6 to 10 minutes and was separated by a 15 minute rest period. For 1 minute before and for the duration of each acquisition, the patient had either ventricular or atrial trigeminy induced by the programmable pacemaker, the order being randomized to eliminate any residual effects of cardiac catheterization on the result of this study. The R-R coupling intervals of the atrial and ventricular premature beats were kept constant for each individual patient to exclude their possible effect on the subsequent potentiation. Each radionuclide study began more than 1 hour after the last contrast injection and took less than 1 hour. At the end, the pacing wires were removed and hemostasis was achieved by compression bandages. No complications were caused by the procedure in any of the 10 patients studied.

Radionuclide analysis: Using the $\mathrm{A}^{2}$ software support program, an R-R histogram was generated from the electrocardiographic gated list mode study. From this, it was usually possible to identify three separate clusters of cardiac cycles. The cluster with the shortest $R-R$ interval represented the cardiac cycle of the interrupted sinus beat, that with the next shortest interval represented the cycle during the postextrasystolic potentiated beat and that with the longest interval represented the cycle during the atrial or ventricular premature heat (Fig. 1). By separately flagging time windows for
R-R HISTOGRAM - VPB STUDY

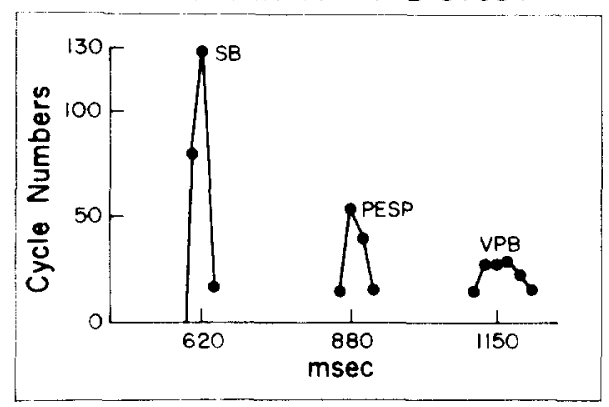

ECG LEAD $V_{1}$

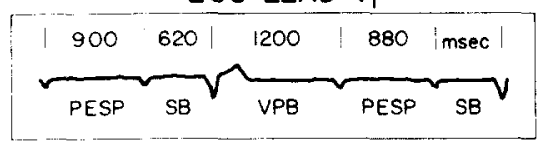

R-R HISTOGRAM - APB STUDY

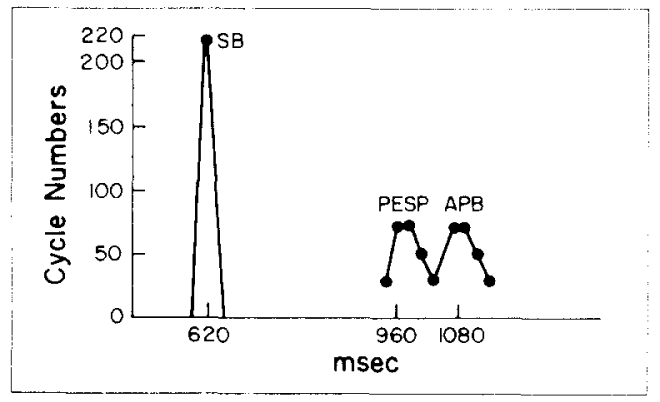

ECG LEAD 2

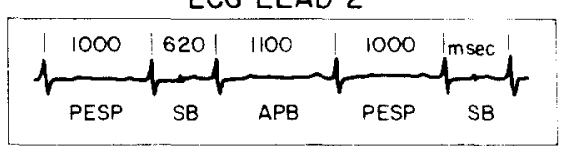

FIGURE 1. Case 4. R-R histograms for the ventricular and atrial stimulation study. Note the longer compensatory pause as well as the faster intrinsic sinus rate of the ventricular stimulation study. $A P B=$ atrial premature beat $R-R$ intervals; $E C G=$ electrocardiogram; $P F S P=$ postextrasystolic beat; $\mathrm{SB}=$ sinus beat; $\mathrm{VPB}=$ ventricular premature beat. 
each of these $R-R$ intervals in turn, radionuclide data were reformatted into a series of 16 to 32 frame 64 by 64 matrix word mode composite cardiac studies representative of each beat in the trigeminal rhythm. The actual time of each acquisition, the number of cardiac cycles accepted and the time/frame of each reformatted cycle were noted for future calculation of relative volume changes.

Three patients had an insufficient compensatory pause after the atrial premature beat to allow its separation from the following potentiated beat. In these studies, the R-R histogram showed only two distinct clusters of cardiac cycles. The first represented the interrupted sinus beat, the second a combination of the premature and potentiated beats. The problem was overcome by using a software option to flag a time window incorporating the second cluster of cardiac cycles. The first of the paired beats that fell within this R-R window was rejected and the second was accepted. Because the potentiated beat always followed the atrial premature beat, this accepted beat always represented the postextrasystolic potentiated cardiac cycle. The atrial premature beat was separated in a different manner. Because this beat always followed the sinus beat by a fixed coupling interval, it was possible to reformat a study containing both beats by selecting the R-R window of the interrupted sinus beat and then choosing an appropriate time/frame and number of frames to encompass the span of both these beats. Once this study was reformatted, the atrial premature beat could then be isolated for independent assessment.

Identification of all the studies was then removed and the order of the composite cardiac cycles was randomized before the analysis of several indexes of left ventricular function. They were then analyzed by observers unaware of the study number and sequence. Left ventricular ejection fraction was calculated using a previously validated semiautomatic method incorporating a second derivative edge algorithm and variable regions of interest. ${ }^{12}$

Analysis of volume changes: The relative end-diastolic and end-systolic volume changes within and between the two stimulation studies and the preliminary study were obtained using the method described by Ritchie et al. ${ }^{13}$ Briefly, to compare the volume changes within each stimulation study, the background-corrected counts contained within the enddiastolic and end-systolic regions of interest were obtained from the composite sinus, premature and potentiated beats. They were then corrected for differences in time/frame and the number of cardiac cycles contained in each study and then expressed as a percent of the values obtained from the appropriate sinus beat. No correction for the decay of technetium $-99 \mathrm{~m}$ is required within such a stimulation study because the three composite beats were acquired simultaneously.

The volume changes occurring between the preliminary and the two stimulation studies were obtained in a similar manner. The background-corrected counts contained within the end-diastolic and end-systolic regions of interest of the composite sinus, atrial and ventricular premature and potentiated beats were once more corrected for individual changes in time/frame and number of cardiac cycles for each. However, they were also corrected for the decay in technetium incurred by the temporal separation of the preliminary and stimulation studies, and this time the values were expressed as a percent of those obtained from the composite sinus beat of the ventricular stimulation study. These volume changes could now be assessed without having to consider the problems of attenuation correction that seem to be necessary for absolute volume measurement. ${ }^{14,15}$

Statistical analysis: Changes in the group data were assessed statistically with use of the two-tailed paired $t$ test.

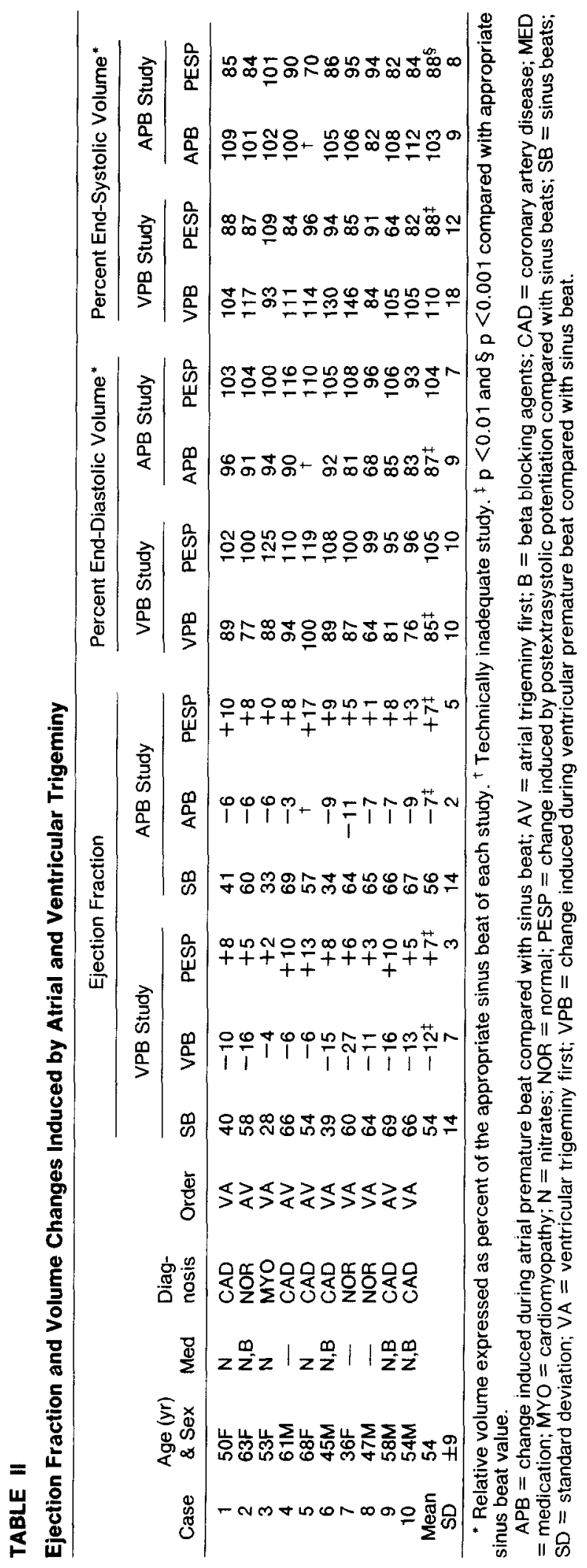


Left Ventricular Function Variables With Normalized Relative End-Diastolic and End-Systolic Volumes ( $\mathrm{n}=10$ patients)

\begin{tabular}{|c|c|c|c|c|c|c|c|}
\hline & \multirow{2}{*}{$\begin{array}{l}\text { Preliminary } \\
\text { Study }\end{array}$} & \multicolumn{3}{|c|}{ VPB Study } & \multicolumn{3}{|c|}{ APB Study } \\
\hline & & SB & VPB & PESP & SB & APB & PESP \\
\hline $\begin{array}{l}\text { Ejection fraction } \\
\text { Rel. EDV\% } \$ \\
\text { Rel. ESV\%§ }\end{array}$ & $\begin{array}{l}56 \pm 14 \\
97 \pm 12 \\
94 \pm 10\end{array}$ & $\begin{array}{c}54 \pm 14 \\
100 \\
100\end{array}$ & $\begin{array}{r}41 \pm 15^{\ddagger} \\
85 \pm 10^{\ddagger} \\
110 \pm 18\end{array}$ & $\begin{array}{c}61 \pm 15^{\ddagger} \\
105 \pm 10 \\
88 \pm 12^{\ddagger}\end{array}$ & $\begin{array}{l}56 \pm 14 \\
96 \pm 12 \\
93 \pm 10^{\dagger}\end{array}$ & $\begin{array}{l}48 \pm 15^{\circ} \\
85 \pm 6^{\dagger} \\
96 \pm 12\end{array}$ & $\begin{array}{r} \pm 15^{\ddagger} \\
101 \pm 10 \\
81 \pm 12^{\ddagger}\end{array}$ \\
\hline
\end{tabular}

Data are expressed as mean \pm standard deviation.

* $p<0.01$ compared with ventricular premature beats. ${ }^{\dagger} p<0.05$ and $\ddagger p<0.01$ compared with the sinus beat of the ventricular premature beat study. $\S$ Volumes are expressed as a percent of the end-diastolic or end-systolic volumes of the sinus beat from the ventricular stimulation study. $\mathrm{EDV}=$ end-diastolic volume; $\mathrm{ESV}=$ end-systolic volume; Rel. = relative; other abbreviations as in Table $I 1$.

Data are expressed as mean \pm 1 standard deviation unless otherwise indicated. For the two paired sets of data, the means \pm 1 standard deviation of the signed differences are presented.

\section{Results}

Mean heart rate, coupling interval and compensatory pause for atrial and ventricular stimulation (Table I): The intrinsic heart rate for the trigeminal rhythm complex was taken to be the R-R interval of the potentiated beat. As expected, there was no significant difference between the coupling intervals of ventricular $(600 \pm 91 \mathrm{~ms})$ and atrial premature beats $(595 \pm 91 \mathrm{~ms})$, and there was a significantly longer compensatory pause after the ventricular premature beat $(1,120 \pm 220$ versus $1,050 \pm 190 \mathrm{~ms}, p<0.01)$. However, the intrinsic cycle length of the ventricular trigeminal rhythm $(850 \pm 160 \mathrm{~ms})$ was significantly shorter than that of the preliminary study $(890 \pm 160$ $\mathrm{ms}, \mathrm{p}<0.01)$ and the atrial stimulation study $(900 \pm 170$ $\mathrm{ms}, \mathrm{p}<0.01$ ); the same trend was evident in all $10 \mathrm{pa}-$ tients. There was no significant difference $(\mathrm{p}>0.1)$ between the intrinsic heart rates of the atrial stimulation and preliminary studies.

Left ventricular ejection fraction and volumes (Table II): Left ventricular function as measured by left ventricular ejection fraction was more seriously compromised during the ventricular premature beat $(-12 \pm 17$ percent) than during the atrial premature beat $(-7 \pm 2$ percent) in eight of nine patients* $(p$ $>0.01$ ). When compared with values of the appropriate sinus beat, the changes in relative end-diastolic volume were almost identical for the ventricular premature $(-15 \pm 10$ percent $)$ and the atrial premature $(-13 \pm 9$ percent) beats, but there was a greater residual endsystolic volume for the ventricular $(10 \pm 18$ percent $)$ than for the atrial $(3 \pm 9$ percent) premature beat. However, this difference did not reach statistical significance.

The mean changes in all left ventricular variables for the postextrasystolic potentiation beat were very similar for the ventricular and atrial stimulation studies. The change in left ventricular ejection fraction was $7 \pm 3$ versus $7 \pm 5$ percent (NS), in relative end-diastolic volume $5 \pm 10$ versus $4 \pm 7$ percent (NS) and in relative end-systolic volume was $-12 \pm 12$ versus $-12 \pm 8$ percent (NS). The mean \pm standard deviations of the signed differences between the changes induced by atrial and ventricular premature stimulation were 0.1 $\pm 2.4(\mathrm{r}=0.91)$ for left ventricular ejection fraction, 1.4 \pm 10 percent for relative end-diastolic volume changes and $-0.1 \pm 10$ percent for relative end-systolic volume changes.

Although there was a small increase in end-diastolic volume during the potentiated beat of the atrial trigeminal study $(+4 \pm 7$ percent $)$ and ventricular trigeminal study $(+5 \pm 10$ percent $)$, neither increase reached statistical significance. However, the changes in end-systolic volume were highly significant for both atrial trigeminy $(-12 \pm 8$ percent, $p<0.01)$ and ventricular trigeminy $(-12 \pm 12$ percent, $p<0.01)$, occurring in 9 of the 10 patients in both stimulation studies.

Relative volume changes for each study: By correcting for the decay of technetium-99m, it was possible to compare the relative volume changes of each study in each individual patient. The values of the normalized volume changes for the study are summarized in Table III and Figure 2. There was a small but insignificant difference in left ventricular ejection fraction and end-diastolic volume of the sinus beat of the ventricular stimulation study when these variables were compared with those obtained from the sinus beats of either the preliminary or the atrial stimulation study. The values for left ventricular ejection fraction and end-diastolic volume of the latter two studies were essentially the same. However, the relative end-systolic volume of the sinus beat of the atrial stimulation $(93 \pm 7$ percent $)$ and the preliminary study ( $94 \pm 10$ percent) appeared to be smaller than the corresponding variable (100 percent) for the ventricular stimulation study, with the former reaching statistical significance $(\mathrm{p}<0.05)$ and the latter just failing to do so $(0.1>\mathrm{p} 0>0.05)$. No other statistically significant differences between the two stimulation studies were found.

To determine whether there was any reduction in the postextrasystolic potentiation with time, changes in left ventricular ejection fraction during the first stimulation study $(+7.3 \pm 4$ percent $)$ were compared with the changes during the second stimulation study $(+6.5 \pm$ 4 percent). These were the same (NS).

\section{Discussion}

Atrial versus ventricular postextrasystolic potentiation: The changes in left ventricular ejection fraction, end-diastolic volume and end-systolic volume during postextrasystolic potentiation were identical 


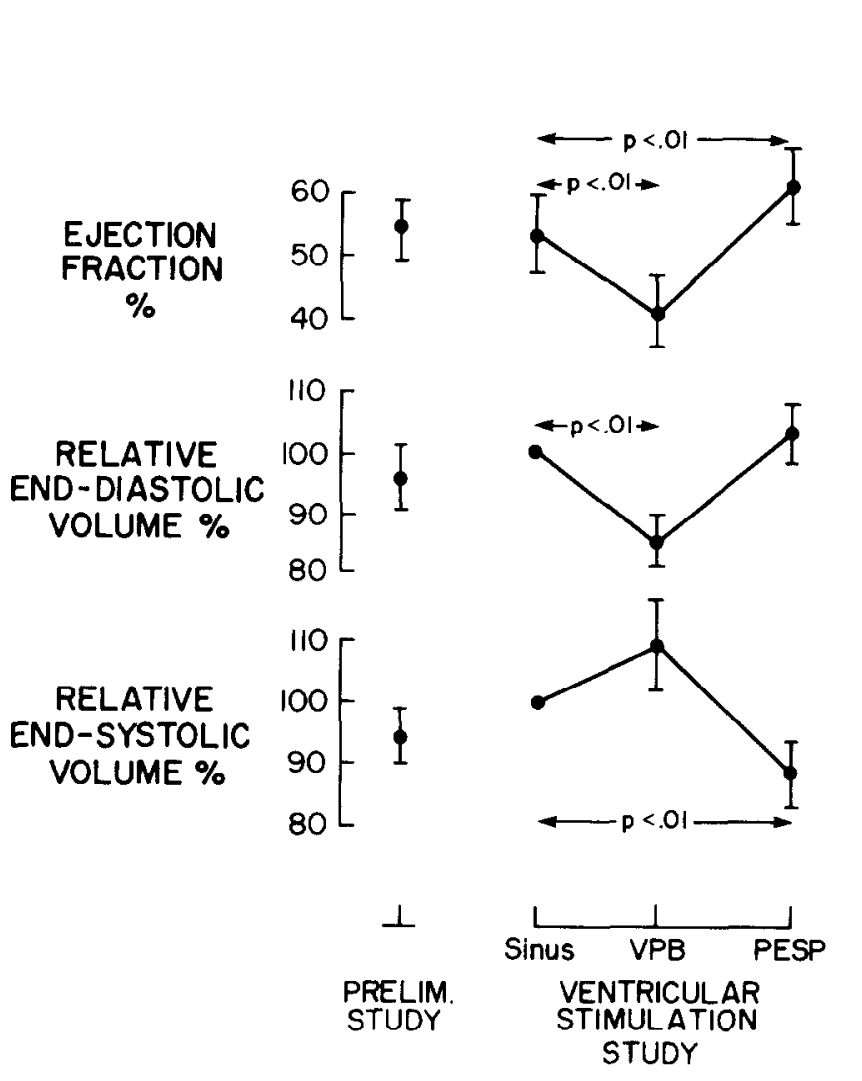
(results mean \pm I SEM) $\mathrm{n}=10 \mathrm{pts}$
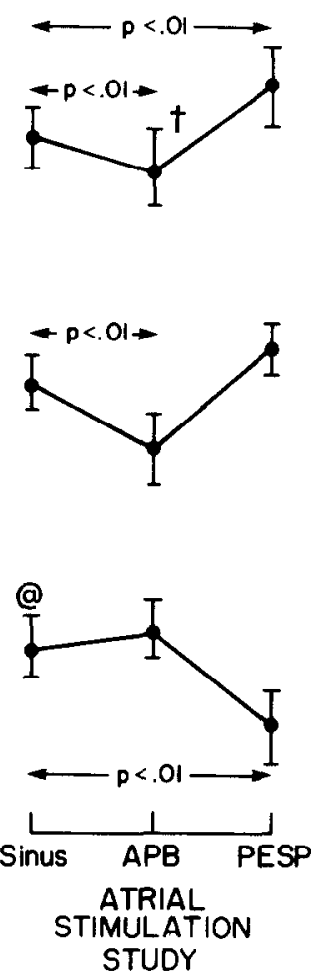

FIGURE 2. Changes in left ventricular function for each study in 10 patients (pts). The relative volumes have been normalized to those of the sinus beat of the ventricular stimulation study. The only statistical difference between each study was the greater reduction in ejection fraction due to the ventricular premature beat (VPB) as compared with the atrial premature beat (APB) $\left({ }^{\dagger} p\right.$ $<0.01)$ and the larger end-systolic volume of the sinus beat of the ventricular stimulation study reaching statistical significance $(p<0.05)$ versus the sinus beat of the atrial stimulation study only. Prelim = preliminary; other abbreviations as in Figure 1.

after either an atrial or a ventricular premature beat when the coupling interval of the premature beat was kept identical. This occurred despite the longer compensatory pause and the greater end-systolic volume at the end of the ventricular premature beat, thus supporting the concept that postextrasystolic potentiation may be an "all or none" phenomenon. ${ }^{16}$

The small but insignificant increase in end-diastolic volume and highly significant decrease in end-systolic volume induced by the postextrasystolic potentiation in this study are in agreement with findings in most previous contrast ventriculographic studies ${ }^{17-19}$ and support the contention that the Starling mechanism plays only a small role in the postextrasystolic potentiation response.

Role of radionuclide ventriculography: This study was performed using radionuclide ventriculography in preference to contrast ventriculography because of the ease of controlling the R-R coupling intervals, the lack of spontaneously induced ectopic activity and the lack of myocardial depression that is usually induced by the contrast materials. The ability of postextrasystolic potentiation to differentiate between viable but ischemic from nonviable or scarred regions of the impaired left ventricle $e^{6-8}$ makes the assessment of regional as well as global left ventricular function an important part of the analysis. The technique of quantitative radionuclide ventriculography has been extensively validated against contrast ventriculography for the assessment of both

global and regional ventricular function at rest and during various interventions. ${ }^{20,21}$ However, regional analysis was not performed in this study because our aim was to compare atrial with ventricular stimulation. Furthermore, it is necessary to acquire the radionuclide studies in the right anterior oblique, left anterior oblique and left lateral views to assess regional function adequately. ${ }^{22}$ The lack of tachyphylaxis between the first and second stimulation studies now makes such acquisition feasible.

Clinical application: The importance of the finding that postextrasystolic potentiation induced by atrial stimulation is the same as that induced by ventricular stimulation lies in the increased ease and safety of performing atrial stimulation in the catheterization laboratory. Atrial postextrasystolic potentiation also may have the potential for allowing noninvasive assessment of postextrasystolic potentiation by combining radionuclide ventriculography with recently introduced esophageal pacing techniques. 23 Thus, il may become feasible to screen noninvasively patients with known impaired left ventricular dysfunction by postextrasystolic potentiation to judge whether they are suitable for surgical intervention.

\section{Acknowledgment}

We thank Anthony Schork, MPH, PhD, Professor of Biostatistics, University of Michigan School of Public Health for statistical advice and Diane Vecellio for editorial and secretarial assistance in the preparation of the manuscript. 


\section{References}

1. Herman MV, Heinle RA, Klein MD, Gorlin R. Localized disorders in myocardial contraction. Asynergy and its role in congestive heart failure. N Engl J Med 1967;277:222-32.

2. Saltiel J, Lesperance J, Bourassa MG, Castonguay Y, Campeau L, Grondin P. Reversibility of left ventricular dysfunction following aortocoronary bypass grafts. AJR 1970;110:739-46.

3. Chatterjee K, Swan JHC, Parmley WW, Sustaita H, Markus HS, Matloff JM. Depression of left ventricular function due to acute myocardial ischemia and its reversal after aortocoronary saphenous vein bypass. $N$ Engl J Med 1972;286:1117-22.

4. Horn HR, Teichholtz LE, Cohn PF, Herman MV, Gorlin K. Augmentation of left ventricular contraction pattern in coronary artery disease by an inotropic catecholamine: the epinephrine ventriculogram. Circulation 1974;49:1063-71.

5. Helfant HH, Pine R, Meister SG, Feldman MS, Trout RG, Banka VS. Nitroglycerine to unmask reversible asynergy. Correlation with post-coronary bypass ventriculography. Circulation 1974;50: $108-13$.

6. Dyke SH, Cohn PF, Gorlin R, Sonnenblick EH. Detection of residual myocardial function in coronary artery disease using postextrasystolic potentiation. Circulation 1974;50:694-9.

7. Hamby RI, Aintabllan A, Wisoff G, Hartstein ML. Response of the left ventricle in coronary artery disease to post extrasystolic potentiation. Circulation 1975;51:428-35.

8. Popio KA, Gorlin R, Bechtel D, Levine JA. Postextrasystolic potentiation as a predictor of potential myocardial viability: preoperative analyses compared with studies after coronary artery bypass surgery. Am J Cardiol 1977;39:944-53.

9. Cohn PF, Gorlin R, Herman M, et al. Relation between contractile reserve and prognosis in patients with coronary artery disease and a depressed ejection fraction. Circulation 1975;51:414-20.

10. Cohn LH, Collins JJ, Cohn PF. Use of the augmented ejection fraction to select patients with left ventricular dysfunction for coronary revascularization. J Thorac Cardiovasc Surg 1976;72: 835-9.

11. Diamond EA, Forrester JS, de Luz PL, Wyatt HL, Swan HJC. Postextrasystolic potentiation of Ischemlc myocardium by atrial stimulation. Am Heart J 1978;95:204-9.

12. Brady T, Thrall JH, Walton JA, Brymer JF, Pitt B. Exercise ra- dionuclide ejection fraction: correlation with exercise contrast ventriculography. Radiology 1979;132:703-5.

13. Ritchie JL, Sorenson SG, Kennedy JW, Hamilton GW. Radionuclide angiography: noninvasive assessment of hemodynamic changes after administration of nitroglycerine. Am $\mathrm{J}$ Cardiol 1979;43:278-84.

14. Dehmer GJ, Lewis SE, Hillis LD, et al. Non-geometric determination of left ventricular volumes from equilibrium blood pool scans. Am J Cardiol 1980;45:293-300.

15. Links JM, Becker LC, Schindledecker JG, et al. Determination of absolute left ventricular volume from gated blood pool imaging with an attenuation corrected count rate method (abstr). Am J Cardiol 1980;45:407.

16. Cohn PF. Evaluation of inotropic contractile reserve in ischemic heart disease using post-extrasystolic potentiation. Circulation 1980;61:1071-5.

17. Hunt D, Burdeshaw JA, Baxley WA. Left ventricular volumes during ventricular tachycardia, first post-tachycardia beat and subsequent beats in normal rhythm. Br Heart J 1974;36:148-53.

18. Schwarz F, Thormann J, Winkler B. Frequency potentiation and postextrasystolic potentiation in patients with and without coronary arterial disease. Br Heart J 1975;37:514-22.

19. Sung CS. Mathur VS, Garcia E, DeCastro CM, Hall RJ. Is postextrasystolic potentiation dependent on Starling's law? Circulation 1980;62:1032-5.

20. Brady TJ, Thrall JH, Keyes JW Jr, Brymer JF, Walton JA, Pltt B. Segmental wall motion analysis in the right ventricular anterior oblique projection: comparison of exercise equilibrium radionuclide ventriculography and exercise contrast ventriculography. J Nucl Med 1980;21:617-721.

21. Berger HJ, Zaret BL. Medical progress: nuclear cardiology. NEngl J Med 1981;305:855-65.

22. Kelly MJ, Glles RW, Simon TR, et al. Multigated equilibrium radionuclide angiography. Improved detection of left ventricular wall motion abnormalities and aneurysms by the addition of the left lateral view. Radiology 1981;139:167-73.

23. Gallagher JJ, Smith WM, Kasell J, Grant AD, Benson DW Jr. Use of the essophageal lead in the diagnosis of mechanisms of reciprocating supraventricular tachycardia. Pace 1980;3:440-4. 